\title{
Gundelia Tournefortii Extracts Inhibit Progressions of Hepatocellular Carcinoma in Mice Model Through Decrease in p53/Akt/PI3K Signaling Pathway
}

Johnny Amer ( $\nabla_{\text {j.amer@najah.edu })}$

An-najah National University Faculty of Medicine and Health Sciences

Nidal Jaradat

An-Najah National University

Hanood Aburas

An-Najah National University

Suhaib Hattab

An-Najah National University

Samer Abdallah

An-Najah National University

\section{Research article}

Keywords: Gundelia tournefortii, cell cycle, Antiproliferative, Apoptosis-inducing, liver cancer

Posted Date: October 29th, 2020

DOI: https://doi.org/10.21203/rs.3.rs-97723/v1

License: (c) (1) This work is licensed under a Creative Commons Attribution 4.0 International License.

Read Full License 


\section{Abstract}

Background: Gundelia (G.) tournefortii is one of the most famous plants used in Palestine for its traditional curative and nutritive properties. We evaluated effects of Gundelia (G.) tournefortii aqueousextract in an ex-vivo and in in-vivo animal model of hepatocellular carcinoma (HCC).

Methods: HCC cell-line (Hep3B) were injected in the back of male mice on NOD.CB17-Prkdc-scid/NCrHsD background. Tumor size, serum a-fetoprotein (aFP) and Glypican-3 (GPC3) were assessed at day 2 following HCC injections till day-12. G. tournifortii extracts were injected i.p at day 10 in HCC mice. Liver histology, hepatic-p53, p-Akt and p-PI3K expressions were evaluated. Primary-hepatocytes from HCC mice were ex-vivo treated with $G$. tournifortii and investigated for perturbation of the DNA cell cycle using propidium iodide $(\mathrm{PI})$ staining assay, while apoptosis was estimated by staining with Annexin- $\mathrm{V}$ and $\mathrm{PI}$ by the flow cytometry.

Results: Tumor mass increase in animals with HCC and was associated with elevated aFP and GPC3 $(P<0.05)$. Mice receiving $G$. tournefortii extracts showed a significant decrease in tumor at days 12 with decreased hepatic-p53 and phosphorylated Akt/PI3K signaling pathway $(p=0.001)$. Histology H\&E staining showed remarkable reduction in inflammatory lesions in HCC livers receiving G. tournifortii extracts in line with delay in G2-M phase of HCC-primary-hepatocytes to 1.39-folds. Moreover, apoptotic activity was mostly enhanced by the $200 \mathrm{mg} / \mathrm{ml} \mathrm{G}$. tournifortii extracts while a reduction of HCC necrosis to 2.4 fold $(P<0.01)$.

Conclusions: Our results explored an anti-cancer, anti-proliferative and apoptotic effects of G. tournifortii in an HCC mice model and in an ex-vivo setting. G. tournifortii could be a promising future cancer remedy.

\section{Background}

Herbal supplements and functional food products have gained increased interest recently due to their nutritional and health benefits. [1-3]. Gundelia (G.) tournefortii is commonly known as Tumble thistle or tumbleweed, and a'kub in Arabic. This annual herbaceous plant belongs to Asteraceae (Compositae) family and native to the Irano-Turanian region and may be found in Mediterranean regions of the east and grow in semi-desert or sandy plains in Palestine, Jordan, Syria, Iraq, Iran, Azerbaijan, Anatolia, Armenia, Turkey and other areas [4-6].

G. tournefortii is a spiny thistle-like perennial plant about $60 \mathrm{~cm}$ height, and its stems branch from the base and almost hairless. Its leaves are leathery, rigid, and alternating with prominent yellow, red, or purple veins; pinnatifid to pinnatisect; with spiny-dentate lobes [6]. While the flower can be white, yellow, burgundy, red or green in color [4]. It has been used to make traditional recipes and have been mentioned in local folkloric songs and proverbs [7]. Its use in food is very ancient, more than 2000 years ago, found in the Talmud of Babylonia and in the Biblical writings [8]. According to al-Muqaddasi, a Jerusalem geographer G. tournefortii was one of the plant species with which Palestine was privileged. Because of 
the excessive commercial gathering of $G$. tournefortii and thus the decline in its population, there were limitations over its gathering to become for domestic use only [9].

The stems, flowers, leaves, and seeds of $G$. tournefortii can be used as food. In Palestine, Jordan, and Syria the tender plants flower buds are collected and cooked before flowering $[4,5]$. In Turkey, dried plant is stacked for winter food, latex is used to make chewing gum and the seeds are used as coffee [10].

In folk medicine, the plant stalk is considered hepatoprotective and blood purifier in Iran and its latex is used for burning off the warts, drying up sores, and as an emetic and a cure for snakebite in Lebanon [4, 5]. Moreover, it used in traditional medicine for the treatment of kidney diseases, anorexia, heart stroke, chest pain, gastric inflammation, diarrhea, bronchitis, gingivitis, vitiligo, and diabetes [4].

The G. tournefortii plant has numerous phytochemical constituents from their aerial parts, root, seed and flower buds but we are interested in the flower bud part, many constituents were isolated from it using a different analytical method, these components include sterol (stigmasterol, B-sitosterol), tocopherols ( $a-$ tocopherol, $\beta$-tocopherol, $\alpha$-tocotrienol, $\beta$-tocotrienol, $\delta$-tocotrienol), fatty acids (arachidic, linolenic, stearic, oleic, palmitic ), minerals ( $\mathrm{Ca}, \mathrm{K}, \mathrm{P}, \mathrm{Mg}, \mathrm{Na})$, crude protein, and water-insoluble fibers [11].

Other sterols were isolated and identified including 5-avenasterol, campesterol, 7-stigmastenol and 7avenasterol while $\beta$-sitosterol was the most predominant one, in addition, vitamin $E$ in the oil was also determined [12]. Previously conducted studies revealed the presence of chlorogenic acid, gallic acid, caffeic acid, terpinen-4-ol, linalool, cymene, limonene, zingiberene, stigmasterol, $\beta$-sitosterol, aesculin, scopoletin and quercetin [11].

One of the fundamental features of cancer is tumor clonality, which means the development of tumors from single cells that begin to proliferate abnormally [12-15]. This process can be retarded by activities such as apoptosis, cytotoxicity, and anti-proliferative activity [16]. According to 2018 WHO statistics, liver cancer was among the most encountered causes of cancer mortality with 782,000 deaths by the end of that year [17 - 9]. For these reasons, the current study aims to determine the anti-hepatocellular cancer activity of $G$. tournefortii in an vivo and ex-vivo models, in specific its' flowering bud part.

\section{Material And Methods}

\section{Plant material and extraction method}

The fresh flowering buds of $G$. tournefortii were purchased from local Palestinian markets (Nablus), the plant was taxonomically characterized in the Pharmacognosy Laboratory at An-Najah National University, and the voucher specimen code is Pharm-PCT-1133. The fresh plant sample was washed several times using distilled water to remove any contaminates.

The cleaned flowering buds of $G$. tournefortii $(200 \mathrm{~g})$ were cut in small pieces and boiled in a beaker with $1 \mathrm{~L}$ of distilled water for $30 \mathrm{~min}$. The boiled mixture was filtered using Buchner funnel. The extract of the sample was lyophilized into a powder form by using a freeze-drier. For cytotoxicity assessment, each $G$. 
tournefortii extracts were diluted in sterile water in a concentration of $100 \mathrm{mg} / \mathrm{ml}$. Cytotoxicity evaluation was carried out by using the primary isolated hepatocytes form HCC mice as compared to their counterparts from the mice received the vehicle treatments.

\section{HCC mice models}

Male mice on NOD.CB17-Prkdc-scid/NCrHsD background, 12 weeks of age, weighing $22 \pm 0.5 \mathrm{~g}$, received care according to ethic regulations of the An-Najah National University and $\mathrm{NIH}$ guidelines. Mice were purchased commercially from Harlan Laboratories, Jerusalem-Israel. All animal protocols were approved by the institutional animal care ethical committee at the An-Najah National University, and housed in a barrier facility. For the xenograft model 3.0 million of Hep3B cells/100ml (human liver hepatocellular carcinoma cell line) were injected subcutaneously at the back ( $\mathrm{N}=6$ animals). Tumor masses and mice weight were daily monitored macroscopically for 12 days at day 2 following cell injections. At day 10 of injections, One group $(\mathrm{N}=6$ ) received $G$. tournefortii extracts made with water were i.p injected at a dose of $60 \mathrm{mg} / \mathrm{kg}$ body weight, while the other group $(\mathrm{N}=6)$ received only the vehicle (100\% water). For tumor serum marker measurements, tail blood samples were drawn every 2 day intervals from each animal starting from day 2 (following Hep3B-injections). At sacrifice (day 12), tumor masses were collected and liver were obtained for both molecular biology and histopathology analyses and tumor size (weight and volumes). Serum samples were obtained for evaluating tumor serum levels. The animals were terminated intramuscularly with $0.1 \mathrm{ml}$ of ketamine: xylazine: acepromazine $(4: 1: 1)$ per $30 \mathrm{~g}$ of body-weight prior to cervical dislocation.

\section{Primary hepatocytes isolations}

Briefly, abdominal area fur were cleaned with $70 \%$ alcohol and a midline incision to expose abdominal site. Livers were perfused from catheter into portal vein with a pump at a rate of $4.5 \mathrm{ml} / \mathrm{minute}$ with perfusion medium (ThermoFisher, Cat \# 17701-038) and later for another 6-7 minutes with liver digest medium (ThermoFisher, Cat \# 17703-034). Livers were then placed in a $100 \mathrm{~mm}$ plate filled with cold $20 \mathrm{ml}$ washing medium, were cut into pieces and transferred through $100 / 70 \mu \mathrm{m}$ filters into $50 \mathrm{ml}$ centrifuge tubes. Cells were centrifuged at $50 \mathrm{Xg}$ for 3 minutes at $4^{\circ} \mathrm{C}$. We decant the supernatant and added $20 \mathrm{ml} 40 \%$ cold percoll (Sigma P1644-500ML) to each tube. We then centrifuged at $150-200 \mathrm{Xg}$ for 7 minutes at $4^{\circ} \mathrm{C}$ and viable hepatocytes were collected from the bottom of the tubes. Washed hepatocytes were cultured in collagen-coated plate at a concentration of $2.2 \times 10^{5}$ cells/ 6-well. Cell were incubated at $37^{\circ} \mathrm{C}$ incubator with $5 \% \mathrm{CO} 2$ for $2.5-3.5$ hours prior to washing once to remove dead cells and a new medium were then placed for additional 24 hours. The next day, medium were changes and hepatocytes were used for our experiments on the next day. Hepatocytes condition was accomplished by using Williams E' medium

(ThermoFisher, Cat number: A1217601) supplemented with 6\% FBS, glutamine, dexamethasone, glucagon and insulin. For the in vitro assay, G. tournefortii extracts made in water were incubated with the obtained primary hepatocytes from the HCC mice model $\left(10^{6} / \mathrm{ml}\right)$ in concentrations of 50,100 and 200 $\mu \mathrm{g} / \mathrm{ml}$ for $24 \mathrm{hrs} / 37^{\circ} \mathrm{C}$. 


\section{Viability assay}

The viability of hepatocytes were determined by trypan blue staining. In briefly, $100 \mu$ l of cells was aseptically transferred to a $1.5 \mathrm{ml}$ clear tube and incubated for $3 \mathrm{~min}$ at room temperature $\left(25^{\circ} \mathrm{C}\right)$ with an equal volume of $0.4 \%(\mathrm{w} / \mathrm{v})$ trypan blue solution (Sigma, USA). Cells were counted using a dual-chamber hemocytometer and a light microscope. Nonviable cells were stained blue and viable cells were unstained. These two types of cells were recorded separately, and the means of six independent cell counts were pooled for analysis.

\section{Histological assessments of liver injury}

The posterior one third of the liver was fixed in 10\% formalin for 24 hours and then paraffin-embedded in an automated tissue processor. Seven-millimeter liver sections were cut from each animal. Sections (15 $\mathrm{mm}$ ) were then stained in $0.1 \%$ Sirius red F3B in saturated picric acid (both from Sigma). Hematoxylin and eosin (H\&E) staining was performed for each animal.

\section{Immunofluorescence staining of liver macrophages}

For deparaffinization, paraffin-embedded sections were placed at $60^{\circ} \mathrm{C}$ for $15 \mathrm{~min}$, incubated in xylene at room temperature for $15 \mathrm{~min}$ and then transferred sequentially into $100 \% \mathrm{EtOH}, 95 \% \mathrm{EtOH}, 70 \% \mathrm{EtOH}$ and $50 \% \mathrm{EtOH}$ for 4 min each at room temperature. Sections were rinsed in deionized water and stored in PBS. For antigen retrieval, we used a buffer ( $10 \mathrm{mM}$ citrate, pH 6.2, 2 mM EDTA and 0.05\% Tween 20) for anti-F480 detection. Samples were incubated with rabbit anti-mouse F480 (diluted 1:170) (IQ Products, Groningen, Netherlands) overnight at $4^{\circ} \mathrm{C}$. After samples were washed with PBS, secondary antibodies conjugated with Cy-2 were applied for 1 hour at room temperature, and image capture was performed. Samples were viewed and imaged with a Zeiss LSM 710 confocal laser-scanning system (Zeiss, Germany) attached to a Zeiss Axiovert 135M microscope, equipped with a Plan-apochromat Zeiss $63 \times$ lens.

\section{Tumor markers by serum ELISA measurements}

Quantitative measurements of mice serum of a-fetoprotein (purchased from abcam; USA) and Glypican-3 (MyBioSource, Inc; USA), were determined according to the manufacture instructions.

\section{Western blot analysis}

Primary hepatocytes protein extracts were prepared in hepatocytes liver homogenization buffer (50 $\mathrm{mmol} / \mathrm{L}$ Tris- $\mathrm{HCl}\left[\mathrm{pH}\right.$ 7.6], 0.25\% Triton-X 100, $0.15 \mathrm{M} \mathrm{NaCl}, 10 \mathrm{mM} \mathrm{CaCl}_{2}$ and complete mini EDTA-free protease inhibitor cocktail (Roche Diagnostics, Mannheim, Germany). Next, proteins (30 $\mu$ g per lane) were resolved on a $10 \%$ (w/v) SDS-polyacrylamide gel (Novex, Groningen, The Netherlands), under reducing conditions. For immunoblotting, proteins were transferred to a Protran membrane. Blots were then incubated for $1 \mathrm{hr}$ at room temperature in a blocking buffer containing 5\% skim milk (w/v). Next, the blots were incubated with rabbit anti-mouse p53/p-AKT/ PI3Ks, (R\&D System, Minneapolis, MN) diluted 1:1000 
overnight in $4^{\circ} \mathrm{C}$, and subsequently, with peroxidase-conjugated with Anti-rabbit (Abcam, Israel, diluted 1/5000), for $1.5 \mathrm{hr}$ at room temperature. Immunoreactivity was detected using an ECL kit (Abcam, Israel).

\section{Flow cytometry analysis}

Following cultures, the adjustment of the harvested primary hepatocytes to $10^{6} / \mathrm{ml}$ in staining buffer (in saline consisting of $1 \%$ bovine albumin was achieved. For viability measurements and apoptosis, the staining of fragmented DNA by propidium-iodide $(\mathrm{PI})$ and the staining of phosphatidylserine by using annexin V-conjugated to FITC was done according to the instructions of the manufacturer (R\&D System, Minneapolis, MN). After that, the apoptosis was marked as annexin-V (+) but propidium-iodide (-). On the other hand, viable cells were marked as annexin-V (-) but propidium-iodide (-). Unstained controls were used in each one of the experiments, such as IgG isotype controls and FMO controls. The analysis of the cell cycle by quantization of DNA content was achieved by employing the propidium-iodide following incubations with the $G$. tournefortii. The fixation of the primary hepatocytes obtained from the HCC animals were performed in a cold $70 \%$ ethanol at $4^{\circ} \mathrm{C}$ for at least $30 \mathrm{~min}$. After that, the cells were washed 2X in PBS. It was calibrated to spin at $2000 \mathrm{rpm}$ to dispose of the supernatant. To make sure that only DNA was stained, the treatment of cells with ribonuclease ( $50 \mu \mathrm{l}$ of $100 \mu \mathrm{g} / \mathrm{ml}$ RNase) was done. Then, cells were stained with $5 \mu \mathrm{l}$ of $50 \mu \mathrm{g}$ Propidium iodide $/ 100 \mathrm{ml}$ and were analyzed using the flow cytometer (Becton-Dickinson LSR II, Immuno-fluorometry systems, Mountain View, CA).

\section{Statistical analysis}

Statistical differences were analyzed either with the 2-tailed unpaired Student's t-test (For comparison between two groups) or one-way analysis of variance (one-way ANOVA with Newman-Keuls' post-tests among multiple groups) using Graph Pad Prism 5.0. Data are shown as means \pm SEM.

\section{Results}

\section{G. tournefortii extracts decreased tumor mass and in part maintained liver histological characteristics in animals with hepatocellular carcinoma (HCC)}

HCC model was performed to study tumorigenicity outcome. Anti-cancer effects of $G$. tournefortii was evaluated through injecting the extracts as mentioned in materials and methods. Hepatic tumor mass and size were obtained at the end of experiment post Hep3B (HCC)-injections. Figure 1a shows macroscopic examination of the tumor extracted from the back of a representative mouse with $\mathrm{HCC}$ and a $\mathrm{HCC}$ mouse receiving the $G$. tournefortii extract as compared with the vehicle mice. Mice with the HCC mouse receiving the $G$. tournefortii extract had tumor size of $0.9 \pm 0.1 \mathrm{~cm}$ as compared to $2.0 \pm 0.6 \mathrm{~cm}$ in the HCC implanted counterparts. Figure 1B shows the gradual increase in tumor size following HCC injections. At day 10, mice groups were split into two groups; one group received the vehicle and the second group received extracts of $G$. tournefortii. Tumor size continued to increase with the vehicle on day 12 post-HCC injections, while HCC implanted mice receiving extracts of $G$. tournefortii showed a significant decrease in tumor size at day $12(p=0.01)$. To characterize whether liver histology is altered 
following the i.p injections of the G. tournefortii extract, we stained for H\&E. The vehicle treatment together with the $G$. tournefortii extract showed no histopathological effects on the liver tissue (Fig. 1c\&d). While the HCC implanted mice group exhibited hemorrhage, necrosis, dysplasia and hepatic cell carcinoma (Fig. 1e); the HCC implanted mice receiving the G. tournefortii extract showed a partial reduction in necro-inflammatory regions and less hemorrhage was observed (Fig. 1f).

HCC progression is known to be driven by chronic inflammation. Macrophages play a crucial role in chronic liver inflammation [18]. The tumor microenvironment plays a key role in the progression of HCC. Tumor-associated macrophages are a well-known component of the tumor microenvironment and abundantly infiltrate HCC microenvironment [19]. The roles of macrophages in the development and progression of HCC have been recognized [20]. For this purpose, immunofluorescence staining of liver macrophages from our mice model groups were examined by confocal microscopy. Images of confocal microscopy show presence of macrophage marker F480 (green) on liver sections obtained from HCC (Fig. 1i) and HCC with the G. tournefortii extract (Fig. 1j). No F480 infiltrates were seen in the vehicle mice treated (Fig. 1h) or untreated (Fig. 1g) with the G. tournefortii extract. To quantify F480 in liver sections, we enumerated cells expressing $\mathrm{F} 480^{+} /$field as indicated in Fig. $1 \mathrm{~K}$. Low numbers of $\mathrm{F} 480^{+}$were observed in liver biopsies of HCC mice treated with the $G$. tournefortii extract as compared to their untreated counterparts, thus indicating fewer infiltrated macrophages and less inflammatory response. $(P=0.0001)$

\section{Serum tumor markers and molecular characteristics of $\mathrm{HCC}$ mice model receiving $\mathrm{G}$. tournefortii extracts}

To further characterize our HCC mice model receiving $G$. tournefortii extracts we evaluated for aFP in order to assess the extent of malignant cells. Moreover, we evaluated for serum levels of GPC3, a heparan sulfate proteoglycan anchored to the plasma membrane. It has been demonstrated to interact with growth factors and modulate their activities. It has been shown that soluble GPC3 is sensitive in detecting well or moderately differentiated HCC [21]. Simultaneous determination of aFP and GPC3 markers improves overall sensitivity from 50-72\% [22]. Figure 3 showed serum aFP (Fig. 3a) levels and GPC3 (Fig. 3b) levels were elevated during tumor progressions at a 2 day intervals following the HCC implantation. Injections with $G$. tournefortii extracts caused a remarkably reduction in both serum aFP and GPC3 levels in the HCC mice models to levels similar to the vehicle treated mice group $(P<0.01)$. To further extend our study on mechanisms behind the decrease in tumor marker following G. tournefortii extracts, we evaluated for molecular signaling in liver extracts though quantitation of phosphorylated proteins by western blot analysis. The tumor suppressor p53 is one of the most frequently mutated genes in liver cancer. p53 regulates expression of genes involved in cell cycle progression, cell death, and cellular metabolism to avert tumor development due to carcinogens [23]. Hepatic intracellular pathways of Protein kinase B (PKB), also known as Akt were evaluated. Akt plays a key role in multiple cellular processes such as glucose metabolism, apoptosis, cell proliferation, transcription, and cell migration [24]. Moreover, Phosphoinositide 3-kinases (PI3Ks) involved in cellular functions such as cell growth, proliferation, differentiation, motility, survival and intracellular trafficking, which in turn are involved in cancer [25] were also assessed. Figure 3c shows densitometry bands of western blot of from 
representative proteins of p53, p-Akt, Akt, p-PI3K, PI3K, and the house keep protein; $\beta$-actin. Average qutanitations of the measured protein are presented in Fig. $3 d-f$. Figure $3 d$ show elevated p53 protein as well as phosphorylated Akt/ PI3K (Fig. 3e\&f) in mice liver extracts receiving the HCC cells as mentioned in materials and methods. Quantitation of p53 protein were decreased and Akt/ PI3K signaling were dephosphorylated in mice liver extracts in $\mathrm{HCC}$ mice receiving $G$. tournefortii extracts $(P<0.05)$. No effects of $G$. tournefortii extracts were seen in naïve mice with or without the treatment. Overall data show that $G$. tournefortii extracts modulated tumor progressions through p53 inhibitions and delay in Akt/PI3K signaling pathway indicating its effects in decreasing proliferations of HCC.

\section{G. tournefortii inhibit DNA cell cycle of HCC isolated primary hepatocytes}

In order to verify the ability of $G$. tournefortii extract to induce disturbances in the cell cycle of hepatocytes of HCC mice, flow cytometry analysis of propidium-iodide stained nuclei cells were used. Perturbations in the cell cycle were investigated using the boiled extracts of $G$. tournefortii, as they exhibited a high efficiency. The extract was diluted in sterile water prior to incubation with hepatocytes at $37^{\circ} \mathrm{C}$ for $24 \mathrm{hrs}$ at a concentration of $100 \mu \mathrm{g} / \mathrm{ml}$. The control cells were treated with water only.

Doxorubicin (Dox) was used to a positive control to induce cell cycle progression [26]. The data in Fig. 3a shows a significant elevation in the proportion of cells in the $\mathrm{G} 1$ phase following treatment with $G$. tournefortii extract. Average values of $52.53 \pm 3.32 \%, 56 \pm 5.56 \%$ and $52.67 \pm 4.04 \%$ were obtained with 50,100 and $200 \mu \mathrm{g} / \mathrm{ml}$ extracts, respectively, as compared to $41.6 \pm 3 \%$ in untreated samples $(P<0.005)$. There was no significant differences between the three different concentrations of the extract. Moreover, a significant decrease in the $S$ phase were seen following the treatments with the extract with the concentration of $200 \mu \mathrm{g} / \mathrm{ml}$ (Fig. 3b). On the other hand, extracts of the three different concentrations inhibited HCC hepatocytes cell cycle in the G2M phase to 3, 6.8 and 2.64-folds following the 50,100 and $200 \mu \mathrm{g} / \mathrm{ml}$ of $\mathrm{G}$. tournefortii extracts, respectively, as compared to untreated cells (percentages obtained were less than the Dox treatments; Fig. 3c). These data show significant disturbances in cell cycle parameters in the G2/M phase (mitosis state) along with a significant shifting to the $\mathrm{G} 1$ phase (naive state), indicating a marked delay in the mitotic phase following $G$. tournefortii extract suggesting a potentials of anti-cancer characteristics.

\section{G. tournefortii increase the apoptotic and necrotic activity of HCC primary hepatocytes in an in vitro cultures}

Phosphatidylserine (PS) one of the phospholipid components of membrane cell, normally PS appears facing the cytoplasm but in case of apoptosis, a flipflop occurs, which means that PS now is facing external surface of the cell [27]. To verify that $G$. tournefortii induce an apoptotic activity in hepatocellular cancer cells isolated from the HCC mice groups, we used Annexin-V, which is a protein with a high affinity to phosphatidylserine, conjugated with FITC for detection of PS. We used another marker, propidium iodide (PI), to check DNA and to determine necrosis (last step of death) in the cells. Early apoptosis evaluated by Annexin- $\mathrm{V}^{+}$and $\mathrm{PI}^{-}$. This was distinguished from late apoptotic and necrotic cells tested (Annexin- $\mathrm{V}^{+}$and $\mathrm{PI}^{+}$) and necrotic cell $\left(\right.$Annexin- $-\mathrm{V}^{-}$and $\mathrm{PI}^{+}$). Three different concentrations of the $\mathrm{G}$. 
tournefortii extracts were used $(50,100$ and $200 \mu \mathrm{g} / \mathrm{ml})$ in order to have a broad spectrum of its apoptotic effects in the in vitro settings. Figure 4 shows that $47.03 \pm 6.2 \%$ of untreated HCC hepatocytes undergone early apoptosis as indicated by Annexin $-\mathrm{V}^{+} / \mathrm{PI}^{-}$. Following treatments with 50,100 and $200 \mu \mathrm{g} / \mathrm{ml}$ the $G$. tournefortii extracts elevated apoptotic activity was noticed up to $55.67 \pm 4.4 \%, 53.67 \pm 4.4 \%$ and $62.67 \pm$ $7.3 \%$, respectively $(P<0.02)$. Moreover, the $G$. tournefortii extracts decreased necrosis effects on the cells (Annexin- $\mathrm{V}^{-}$and $\mathrm{Pl}^{+}$) in favor to shifting the cells for late apoptosis and necrosis (Annexin- $\mathrm{V}^{+}$and $\mathrm{Pl}^{+}$) in a range of 1.4 to 1.8 -fold increase $(P<0.004)$. Our data strongly suggest that $G$. tournefortii has an anticancer property through increasing the apoptotic and necrotic activity of hepatocellular cancer cells and thus shifting the cells to program cell death rather than causing death to the cells.

\section{Discussion}

Several studies were conducted to study anti-cancer properties of plants including Gundelia species. However, these papers only discussed one anticancer aspect and were focused in testing the extract in an in vitro setting. On the other hand, our study discussed the anticancer activity on liver cancer in both an in vivo animal model and ex-vivo hepatocellular carcinoma cells isolated from mice livers. Other studies on the anticancer activity of $G$. tournefortii were conducted by Saleh Abu-Lafı et al. [28] and Betül Özaltun and Taner Dastan [29]. Abu-Lafi et al. found that methanol and hexane extracts of $G$. tournifortii showed anti-cancer properties against the HCT-116 cancer cell line. However, the water extract showed no significant effects were achieved. On the other hand, Betül Özaltun and Taner Dastan found that aqueous plant extracts of different concentrations obtained from different parts exhibited potent cytotoxic activity against human breast adenocarcinoma cell (MCF-7). In our current study, we choose to use G. tournifortii extracts in water solution to prevent any potential harm and hepatotoxicity with other organic solvent. We showed that the flower buds of $G$. tournifortii suggest an interesting anticancer agent that can potentially act on several levels of the cell cycle including inhibited molecular expressions of p53 and cell proliferations through Akt/PI3K, arresting the most attractive phase of mitosis (G2-M phase) and enhancing cell apoptotic activity. These anti-proliferative effects could be explain in part as suppression of serum tumor marker of aFP and GPC3.

Akt, also known as protein kinase B, plays key roles in cell proliferation, survival and metabolism. Akt hyperactivation contributes to many pathophysiological conditions, including human cancers [30, 31], and is closely associated with poor prognosis and chemo- or radiotherapeutic resistance [31]. Normally, Akt is activated by growth factors that activate PI3K; both Akt and PI3K were inhibited following treatments of $G$. tournifortii. Human hepatocellular carcinoma (HCC) is the most common primary malignancy of the liver [32,33], and represents a severe, worldwide threat to human health and quality of life. Patient survival after surgery remains relatively low, with 5-year survival rates after resection for earlystage disease ranging between 17 and $53 \%$, and recurrence rates being as high as $70 \%[34,35]$. Therefore, it is important to identify biomarkers that reliably distinguish patients at high risk of recurrence. G. tournifortii could contribute to the medicinal treatment of liver cancer and could be used a target for Akt activation and thus interfere with cell signaling responses and cycle checkpoints. 


\section{Conclusions}

G. tournifortii extract suppressed cell proliferation and induced apoptosis in primary liver hepatocytes isolated from HCC mice through inhibiting Akt and PI3K phosphorylation. Less HCC proliferations were also confirmed through decrease in serum levels of aFP and GPC3. Moreover, treatment with $G$. tournifortii extract significantly delayed G2/M phase of cell cycle progression and shifted the cells to G1 phase, and was associated to inhibition of phosphorylation of p53in the tumor. Our findings suggest that $G$. tournifortii extract has potential as an anti-cancer treatment. This is the first report concerning $G$. tournifortii extract effects in animal model of liver cancer.

\section{Abbreviations}

G. tournifortii

Gundelia tournefortii; aFP:a-fetoprotein; GPC3:Glypican-3; HCC:hepatocellular carcinoma;

\section{Declarations}

\section{Ethics approval}

The institutional animal care ethical committee at An-Najah National University approved all animal protocols and mice were housed in a barrier facility.

\section{Consent for publication}

The authors indicated no potential conflicts of interest.

\section{Availability of data and materials}

Data is available from the corresponding author upon reasonable request.

\section{Competing interests}

The authors indicated no potential conflicts of interest.

\section{Funding}

Not applicable

\section{Authors' contributions}

JA performed and designed the experiments, wrote the manuscript; $\mathrm{NJ}$ collected the plant and made the extracts; HA performed the pathological assessments; $\mathrm{SH}$ revised the manuscript SA analyzed the data. All authors have read and approved the manuscript in its current state.

\section{Acknowledgment}


We would like to thank Mr. Mohammad Arar from Faculty of Pharmacy for reagents supply and orders.

\section{References}

1. Aschwanden C. Herbs for health, but how safe are they? Bulletin of the World Health Organization. 2001;79:691-2.

2. Mainardi T, Kapoor S, Bielory L. Complementary and alternative medicine: herbs, phytochemicals and vitamins and their immunologic effects. Journal of Allergy and Clinical Immunology. 2009;123(2): 283-94.

3. Groden SR, Woodward AT, Chatters LM, Taylor RJ. Use of complementary and alternative medicine among older adults: differences between baby boomers and pre-boomers. The American Journal of Geriatric Psychiatry. 2017; 25(12): 1393-401.

4. Asadi-Samani M, Rafieian-Kopaei M, Azimi N. Gundelia: a systematic review of medicinal and molecular perspective. Pakistan journal of biological sciences: PJBS. 2013;16(21):1238-47.

5. Lev-Yadun S, Abbo S. Traditional use of A'kub (Gundelia tournefortii, Asteraceae), in Israel and the Palestinian authority area. Economic botany. 1999; 217-9.

6. Ceylan S, Cetin S, Camadan Y, Saral O, Ozsen O, Tutus A. Antibacterial and antioxidant activities of traditional medicinal plants from the Erzurum region of Turkey. Irish Journal of Medical Science. 2019; 1 -7.

7. Ali-Shtayeh MS, Jamous RM, Al-Shafie JH, Elgharabah WA, Kherfan FA, Qarariah KH, et al. Traditional knowledge of wild edible plants used in Palestine (Northern West Bank): a comparative study. Journal of Ethnobiology and Ethnomedicine. 2008; 4(1):13.

8. Boi M. The Ethnocultural significance for the use of plants in Ancient Funerary Rituals and its possible implications with pollens found on the Shroud of Turin. Congreso Internacional sobre la Sábana Santa en España; Spain: Valencia. 2012; 1-20.

9. Mayer-Chissick U, Lev E. Wild Edible Plants in Israel Tradition Versus Cultivation. Medicinal and Aromatic Plants of the Middle-East: Springer. 2014; 9-26.

10. Bagcı E, Hayta S, Kılıc O, Kocak A. Essential oils of two varieties of Gundelia tournefortii L. (Asteraceae) from Turkey. Asian Journal of Chemistry. 2010; 22(8): 6239-44.

11. Asadi-Samani M, Rafieian-Kopaei M, Azimi N. Gundelia: a systematic review of medicinal and molecular perspective. Pakistan Journal of biological sciences. 2013; 16(21): 1238-47.

12. Matthäus B, Özcan M. Chemical evaluation of flower bud and oils of tumbleweed (Gundelia tourneforti L.) as a new potential nutrition sources. Journal of food biochemistry. 2011; 35(4): 125766.

13. Kieliszek M, Lipinski B, Błażejak S. Application of sodium selenite in the prevention and treatment of cancers. Cells. 2017; 6(4): 39.

14. Farkona S, Diamandis EP, Blasutig IM. Cancer immunotherapy: the beginning of the end of cancer? BMC medicine. 2016;14(1): 73. 
15. Cooper GM. The Cell: A Molecular Approach. 2nd edition ed: Sunderland (MA): Sinauer Associates; 2000.

16. Bender T, Martinou JC. Where killers meet-permeabilization of the outer mitochondrial membrane during apoptosis. Cold Spring Harbor perspectives in biology. 2013; 5(1): a011106.

17. Zhu Y-P, Chen Y-M, Matro E, Chen R-B, Jiang Z-N, Mou Y-P, et al. Primary hepatic angiosarcoma: a report of two cases and literature review. World Journal of Gastroenterology 2015;21(19): 6088.

18. Krenkel O, Tacke F. Liver macrophages in tissue homeostasis and disease. Nat Rev Immunol. 2017; 17: 306-21.

19. Hernandez-Gea V, Toffanin S, Friedman SL, Llovet JM. Role of the microenvironment in the pathogenesis and treatment of hepatocellular carcinoma. Gastroenterology. 2013;144(3):512-527.

20. Hou XJ, Ye F, Li XY, Liu WT, Jing YY, Han ZP, et al. Immune response involved in liver damage and the activation of hepatic progenitor cells during liver tumorigenesis. Cell Immunol. 2018;326:52-59.

21. Aikawa T, Whipple CA, Lopez ME, Gunn J, Young A, Lander AD. et al. Glypican-1 modulates the angiogenic and metastatic potential of human and mouse cancer cells. The Journal of clinical investigation. 2008;118: 89-99.

22. Capurro M, Filmus J. Glypican-3 as a serum marker for hepatocellular carcinoma. Cancer Res. 2005;1:65(1), 372.

23. Vousden KH, Ryan KM. p53 and metabolism. Nat Rev Cancer. 2009; 9:691-700.

24. Henderson V., Smith B., Burton L.J., Randle D., Morris M., Odero-Marah V.A. Snail promotes cell migration through Pi3K/Akt-dependent rac1 activation as well as Pi3K/Akt-independent pathways during prostate cancer progression. Cell Adhes. Migr. 2015;9: 255-264.

25. Vivanco I, Sawyers CL. The phosphatidylinositol 3-Kinase AKT pathway in human cancer. Nat Rev Cancer. 2002;2:489-501.

26. Chang, C. C., Liang, Y. C., Klutz, A., Hsu, C. I., Lin, C. F., Mold, D. E., et al. Reversal of multidrug resistance by two nordihydroguaiaretic acid derivatives, M4N and maltose-M3N, and their use in combination with doxorubicin or paclitaxel. Cancer Chemother. Pharmacol. 2006;58:640-653.

27. Calderon F., Kim H.-Y. Detection of intracellular phosphatidylserine in living cells. J. Neurochem. 2008;104:1271-1279.

28. Abu-Lafi S, Rayan B, Kadan S, Abu-Lafi M, Rayan A. Anticancer activity and phytochemical composition of wild Gundelia tournefortii. Oncology letters. 2019,17(1): 713-7.

29. Özaltun B, Daştan T. Evaluation of Antimicrobial Activities and In Vitro Cytotoxic Activities of Gundelia tournefortii L. Plant Extracts. SDÜ Tıp Fakültesi Dergisi. 2019; 26(4):436-42.

30. Liu P, Begley M, Michowski W, Inuzuka H, Ginzberg M, Gao D, Tsou P, Gan W, Papa A, Kim BM, Wan L, Singh A, Zhai B, Yuan M, Wang Z, Gygi SP, Lee TH, Lu KP, Toker A, Pandolfı PP, Asara JM, Kirschner MW, Sicinski P, Cantley L, Wei W. Cell-cycle-regulated activation of Akt kinase by phosphorylation at its carboxyl terminus. Nature. 2014; 24:508(7497): 541-5 
31. Luo J, Manning BD, Cantley LC. Targeting the PI3K-Akt pathway in human cancer: rationale and promise. Cancer Cell. 2003; 4:257-262.

32. Ferlay J, Soerjomataram I, Dikshit R, Eser S, Mathers C, Rebelo M, et al. Cancer incidence and mortality worldwide: sources, methods and major patterns in GLOBOCAN 2012. Int J Cancer. 2015;136: E359-86.

33. Zheng J, Chou JF, Gonen M, Vachharajani N, Chapman WC, Majella Doyle MB, et al. Prediction of hepatocellular carcinoma recurrence beyond milan criteria after resection: validation of a clinical risk score in an international cohort. Ann Surg. 2017; 266: 693-701.

34. Chen XP, Qiu FZ, Wu ZD, Zhang ZW, Huang ZY, Chen YF. Long-term outcome of resection of large hepatocellular carcinoma. Br J Surg. 2006;93:600-6.

35. Ruan DY, Lin ZX, Wang TT, Zhao H, Wu DH, Chen J, et al. Nomogram for preoperative estimation of long-term survival of patients who underwent curative resection with hepatocellular carcinoma beyond Barcelona clinic liver cancer stage A1. Oncotarget. 2016; 7: 61378-89.

\section{Figures}

a Vehicle

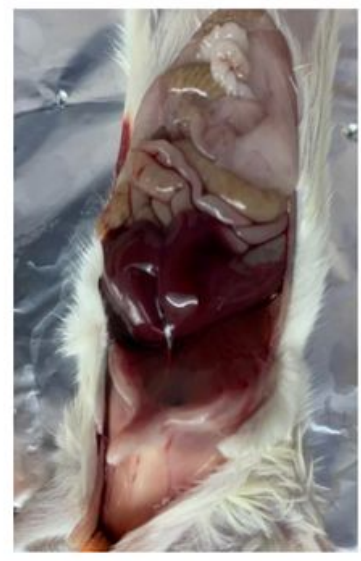

b

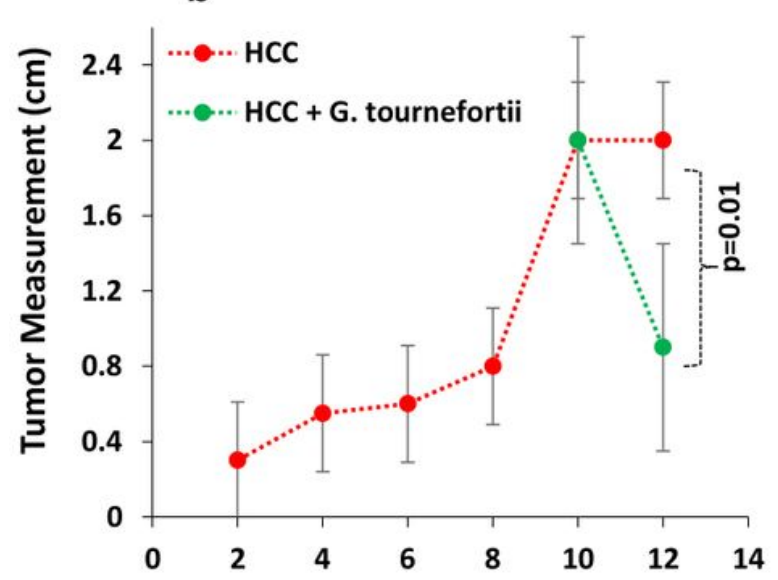

Days post Hep3B injections
HCC
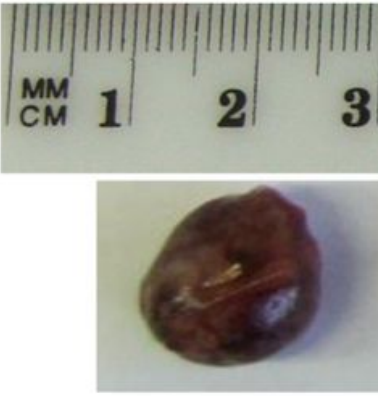

$2 \mathrm{~cm}$
HCC + G. tournefortii

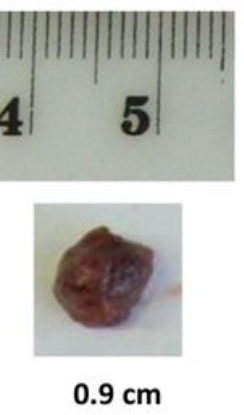

$0.9 \mathrm{~cm}$

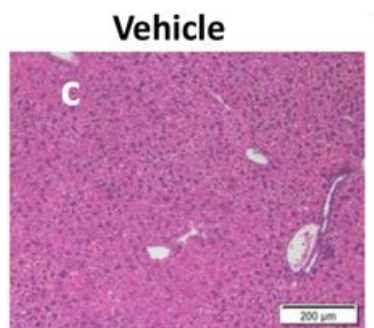

HCC

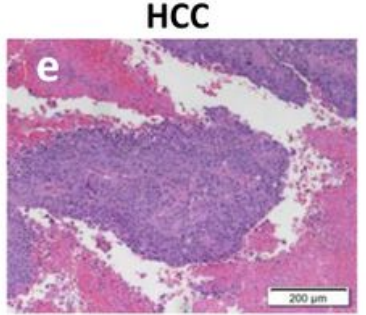

Vehicle+ G. tournefortii

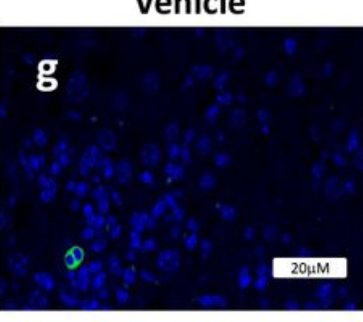

HCC

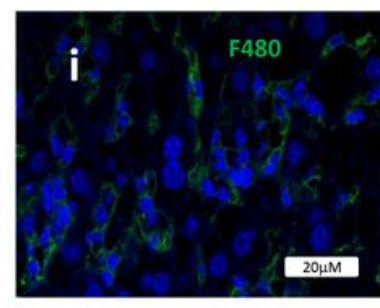

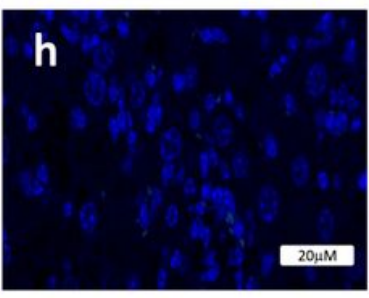

$\mathrm{HCC}+$ G. tournefortii

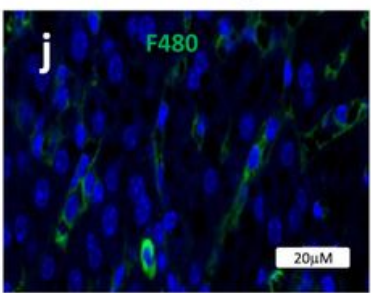

Vehicle+ G. tournefortii

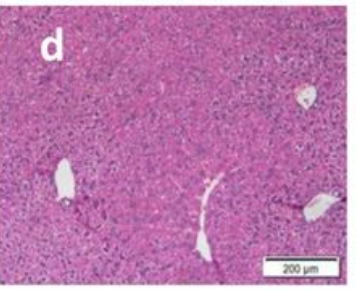

HCC+ G. tournefortii
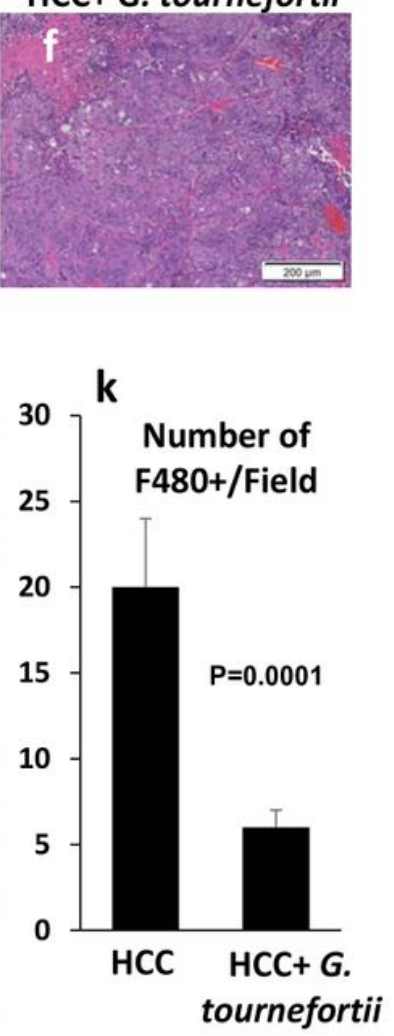
Figure 1

Liver histology, tumor measurements and inflammation with G. tournifortii. a. Tumors extracted from the back of the mice and measured in $\mathrm{cm}$ at the end of the sacrifice day. Vehicle treated mice shows no evidence of tumors and liver are macroscopically normal. b. Kinetic measurements of tumor size performed on tumors on the back of the mice. c-f. H\&E staining of liver sections from mice groups. g-j. Confocal microscopy of F480 expressions on macrophages from liver sections (X63 resolution). $\mathrm{k}$. Averages of umber of F480+/Field in HCC mice with and without with G. tournifortii.
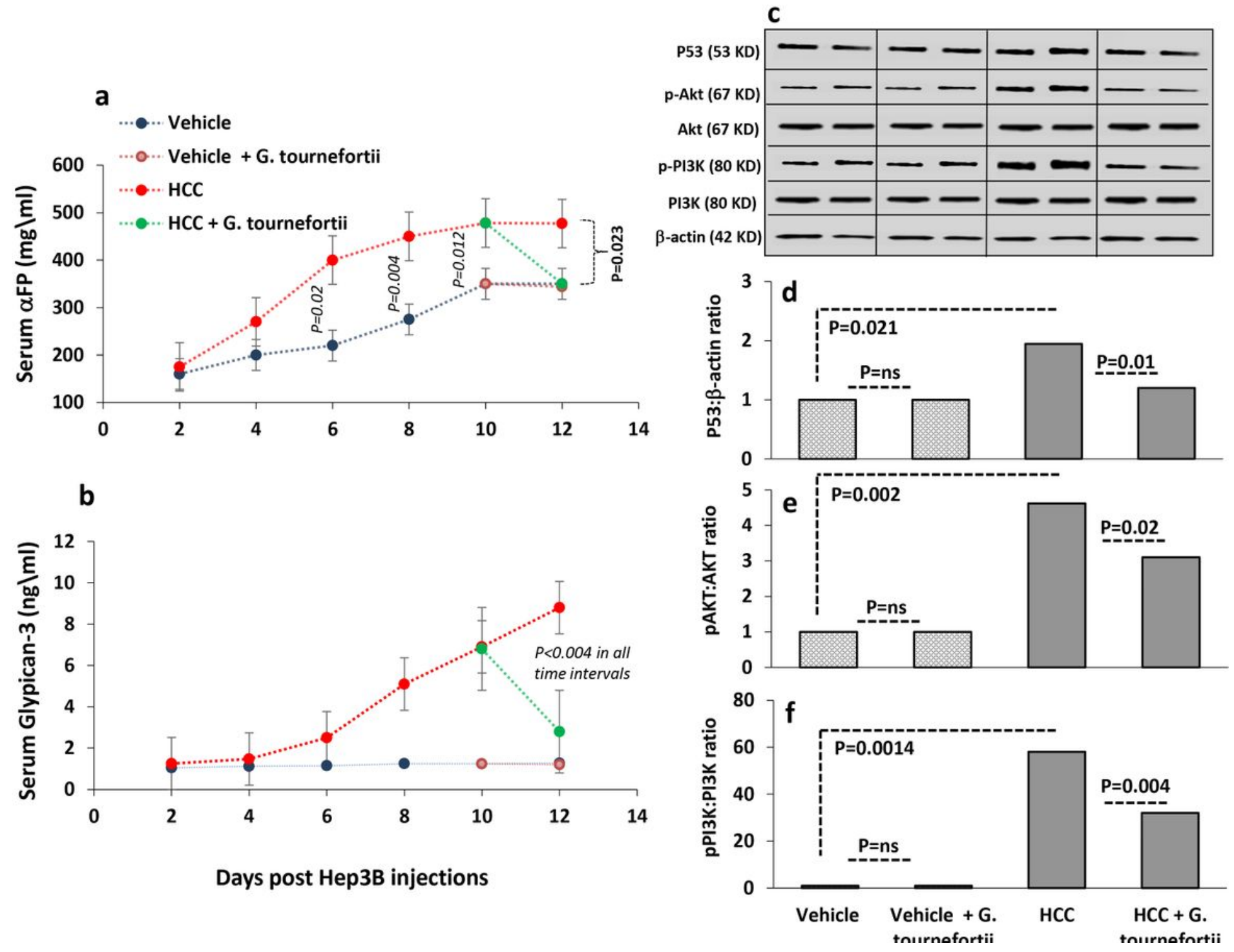

Figure 2

Anti-cancer effects of G. tournifortii extract. Serum tumor markers of (a.) aFP and (b.) Glypican-3 assessed by ELISA. c. Densitometry blot band readings of western blot. Average quantitation's of the ratios of hepatic expressions of (d.) p53 (e.) p-Akt and (f.) p-PI3K assessed by western blot analysis. 


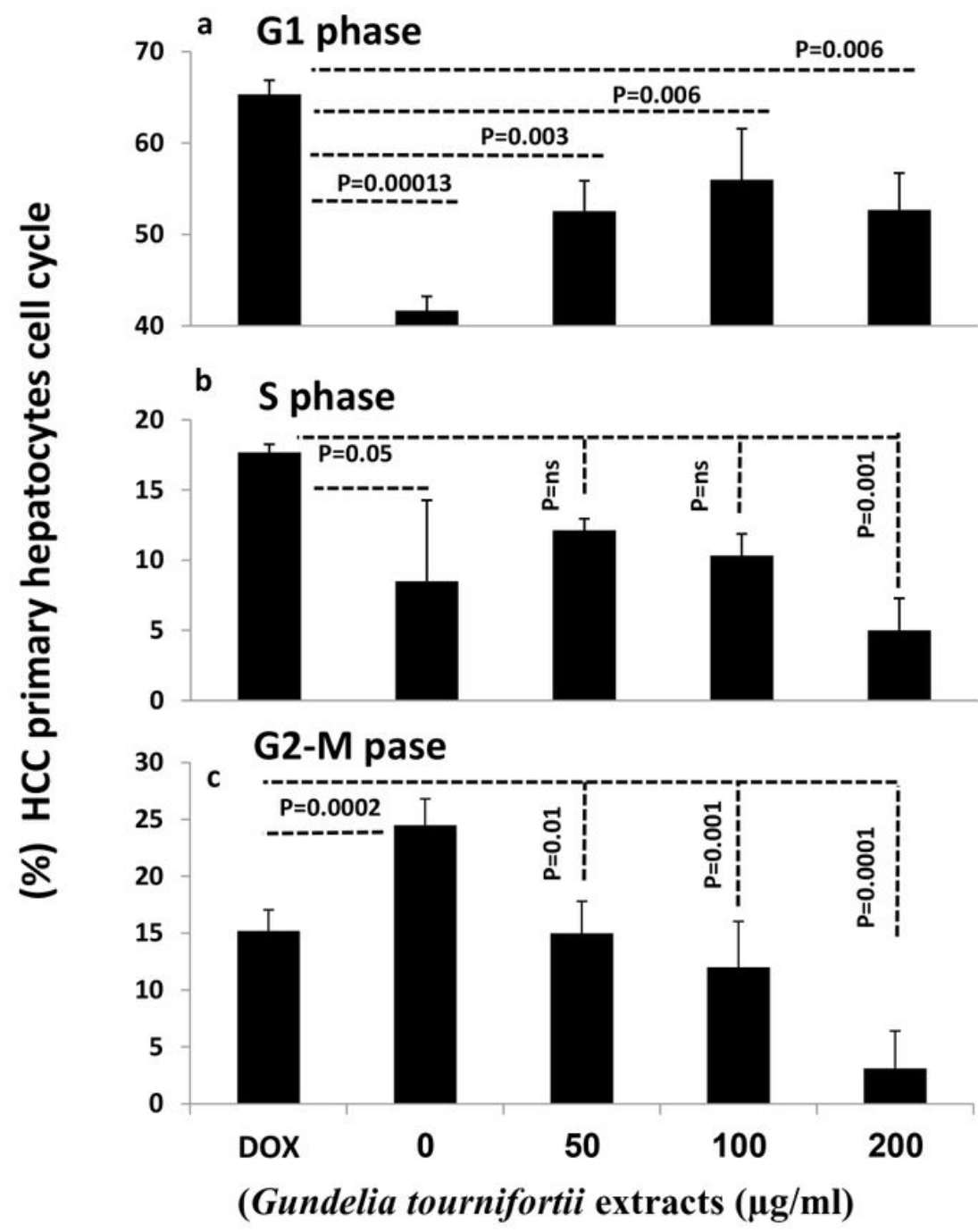

Figure 3

Cell cycle staining through PI as described in materials and methods. The figure shows averages of 3 different readings of (a.) G1 phase (b.) S phase and (c.) G2-M phase following treatments with different concentrations $\mathrm{G}$. tournifortii extract. 


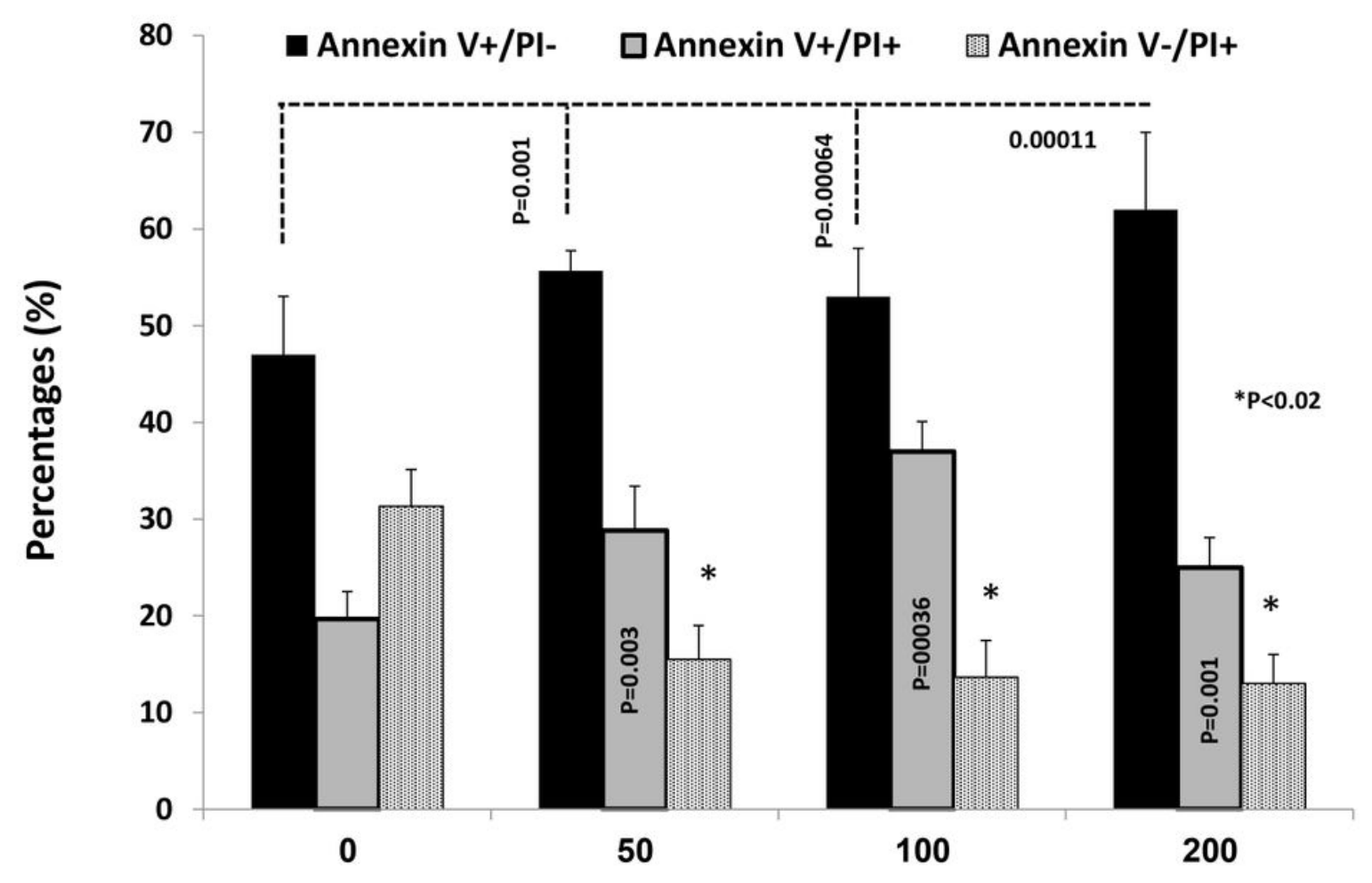

(Gundelia tournifortii extracts $(\mu \mathrm{g} / \mathrm{ml})$

Figure 4

Averages of the apoptotic and necrotic markers of HCC primary hepatocytes following treatments with G. tournifortii. Cells were stained for apoptosis markers (Annexin-V-FITC) and necrotic marker (PI-PE). Primary hepatocytes were treated with 50,100 and $200 \mu \mathrm{g} / \mathrm{ml}$ of $\mathrm{G}$. tournifortii extracts. Apoptosis and necrosis averages $\pm S D$ of are shown. For statistically significant differences, paired and unpaired student t-test and analysis of variance were used.

\section{Supplementary Files}

This is a list of supplementary files associated with this preprint. Click to download.

- Wersternblotsoriginblots.pdf

- TheARRIVEGuidelinesChecklist.pdf 